\title{
Social Information Processing and Cardiac Predictors of Adolescent Antisocial Behavior
}

\author{
Joseph C. Crozier, Kenneth A. Dodge, \\ Reid Griffith Fontaine, and Jennifer E. Lansford \\ Duke University
}

\author{
Gregory S. Pettit \\ Auburn University
}

\author{
John E. Bates \\ Indiana University
}

\begin{abstract}
The relations among social information processing (SIP), cardiac activity, and antisocial behavior were investigated in adolescents over a 3-year period (from ages 16 to 18) in a community sample of 585 (48\% female, 17\% African American) participants. Antisocial behavior was assessed in all 3 years. Cardiac and SIP measures were collected between the first and second behavioral assessments. Cardiac measures assessed resting heart rate (RHR) and heart rate reactivity (HRR) as participants imagined themselves being victimized in hypothetical provocation situations portrayed via video vignettes. The findings were moderated by gender and supported a multiprocess model in which antisocial behavior is a function of trait-like low RHR (for male individuals only) and deviant SIP. In addition, deviant SIP mediated the effects of elevated HRR reactivity and elevated RHR on antisocial behavior (for male and female participants).
\end{abstract}

Keywords: antisocial behavior, heart rate, social information processing, adolescents

Antisocial behavior problems in children and adolescents are known to relate to specific patterns of cardiac activity (Raine, 1996) and deviant social information processing (SIP; Crick \& Dodge, 1994; Dodge \& Schwartz, 1997). Measures of cardiac activity include both baseline physiological arousal (tonic activity) and physiological reactivity to stimuli (phasic activity). Measures of SIP include the social skills and cognitive heuristics that children use to construct competent behavioral responses to social stimuli. One important criticism of SIP approaches to understanding antisocial behavior is that these approaches do not adequately account for the role of affective processes (Lemerise \& Arsenio, 2000). In addition, an important limitation of the literature linking cardiac activity to antisocial behavior is that although the main effects have been well documented, there is much less empirical

Joseph C. Crozier, Department of Psychology, Duke University; Kenneth A. Dodge, Reid Griffith Fontaine, and Jennifer E. Lansford, Center for Child and Family Policy, Duke University; John E. Bates, Department of Psychology, Indiana University; Gregory S. Pettit, Department of Human Development and Family Studies, Auburn University; Robert W. Levenson, Department of Psychology, University of California, Berkeley.

The Child Development Project is an ongoing longitudinal study of the development of conduct problems in children and adolescents conducted jointly by Kenneth A. Dodge, John E. Bates, and Gregory S. Pettit and supported by grants from the National Institute of Mental Health (Grants MH42498, MH56961, MH57024, and MH57095) and the National Institute of Child Health and Human Development (Grant HD30572).

Correspondence concerning this article should be addressed to Joseph C. Crozier, Box 90085, Department of Psychology: Social and Health Sciences, Duke University, Durham NC 27708-0085. E-mail: Joseph.Crozier@duke.edu work examining proposed psychological mechanisms that may mediate the link between cardiac activity and antisocial behavior. The current study aimed to address these limitations by examining how affective processes, as indexed by cardiac activity, are coordinated with SIP in explaining concurrent and future antisocial behavior in adolescence. As such, cardiac activity and SIP were examined as potential mediators of the main effect of each other on antisocial behavior. To this end, online measures of both cardiac activity and SIP in response to hypothetical provocations were collected and related to antisocial behavior across time in a community sample of adolescents.

\section{Antisocial Behavior and SIP}

SIP theory posits that social behavior occurs as a function of a series of online mental operations in response to external and internal stimuli. Crick and Dodge (1994) posited multiple sets of cognitive operations that contribute to behavioral outcomes: (a) encoding of external and internal stimulus cues, (b) interpretation and attribution of the stimulus, (c) clarification of one's goals, (d) response access or construction, (e) response evaluation and decision, and (f) behavioral enactment. Central to the SIP model is the hypothesis that patterns of processing at each step develop over time as a function of transactions among biological and experiential factors across development (Dodge \& Pettit, 2003; Fontaine \& Dodge, in press). It is further theorized that, in a given situation, these mental operations occur in real time in response to social cues, are influenced by biological states and acquired social knowledge, and may involve both controlled and automatic processes (de Castro, 2004; Dodge, Coie, \& Lynam, 2006). 
Deviant patterns of processing at each step in the SIP model have been linked to aggressive and antisocial behavior in children and adolescents (Crick \& Dodge, 1994; Dodge et al., 2006; Dodge \& Schwartz, 1997). Antisocial behavior is associated with selective attention to hostile cues (Gouze, 1987), a hostile attributional bias involving a tendency to interpret ambiguous social cues as threatening (de Castro, Veerman, Koops, Bosch, \& Monshouwer, 2002), a greater likelihood of pursuing hostile goals during interpersonal encounters (Slaby \& Guerra, 1988), greater ease in accessing aggressive responses to social cues (Dodge et al., 2003), and a greater tendency to evaluate aggressive behavior as being morally appropriate and effective for pursuing social goals (Fontaine, Burks, \& Dodge, 2002; Fontaine \& Dodge, 2006).

\section{Antisocial Behavior and Cardiac Activity}

The relation between measures of autonomic nervous system (ANS) activity and antisocial behavior in children and adolescents has been examined using a variety of approaches since the 1970s (see Raine, 1993, 1996, for reviews). One of the most commonly used autonomic measures is heart rate (HR) because it can be obtained relatively easily using noninvasive techniques and has been the most reliable physiological correlate of aggressive and antisocial behavior (Raine, 2002). HR has been examined while participants are at rest and during various types of challenges. Measurement at rest indexes the tonic level of ANS activity, that is, homeostatic regulation, whereas measurement during challenge or stimuli presentation indexes phasic ANS activity and provides insight into the dynamic process of reactivity and self-regulation (Porges, Doussard-Roosevelt, Portales, \& Greenspan, 1996).

Studies examining resting HR (RHR) have generally found that aggressive/antisocial children and adolescents display lower RHRs than their nonaggressive peers. Two recent meta-analyses support this conclusion (Lorber, 2004; Ortiz \& Raine, 2004). Ortiz and Raine (2004) collapsed across age groups and antisocial behavior types and found that across 45 independent samples, the average effect size $(d)$ was -0.4 . Despite significant heterogeneity in effect sizes across studies, the authors found no systematic evidence for moderation by gender, age, type of control group (psychiatric versus healthy), method for collecting HR, study design (concurrent vs. prospective), source of the sample participants, or behavioral rater. Lorber (2004) examined the relation between RHR and antisocial behavior across three age groups (children, adolescents, and adults) and across three types of antisocial behaviors (aggression, psychopathy/sociopathy, and conduct problems). By summing across age groups, the author found that RHR was significantly negatively related to aggression $\left(d_{+}=-0.38\right)$ and conduct problems $\left(d_{+}=-0.33\right)$ but not to psychopathy/sociopathy $\left(d_{+}=\right.$ 0.06). When age groups were examined separately, the negative relation between aggression and RHR was significant for children $\left(d_{+}=-0.51\right)$ and adults $\left(d_{+}=-0.30\right)$ but not for adolescents $\left(d_{+}=-0.15\right)$; however, the negative relation between conduct problems and RHR remained significant for both children $\left(d_{+}=\right.$ $-0.34)$ and adolescents $\left(d_{+}=-0.35\right)$. In addition to the concurrent relation between RHR and antisocial behavior, criminal behavior in adulthood has been linked to low RHR in longitudinal studies of children (Wadsworth, 1976) and adolescents (Farrington, 1987; Raine, Venables, \& Williams, 1990). In contrast, high RHR is associated with a decreased likelihood for criminal behavior in adulthood among antisocial (Raine, Venables, \& Williams, 1995) and high-risk (Brennan et al., 1997) adolescents.

Raine (2002) hypothesized two possible psychological explanations for the robust relation between low RHR and aggressive/ antisocial behavior: (a) a low tonic level of autonomic activity is a marker of fearlessness, which contributes to antisocial behavior by lowering the deterrent value of potential retaliation and punishment; and (b) chronically low tonic autonomic activity is an uncomfortable state that motivates behaviors such as aggressive/ antisocial acts that raise arousal to more optimal levels. In addition, Raine (2002) hypothesized several possible physiological mechanisms that might account for the relation between low HR and antisocial behavior, including increased vagal tone, decreased noradrenergic tone, and reduced right-hemisphere functioning. The data available on the physiological mechanisms provide limited support for decreased noradrenergic tone and reduced righthemispheric functioning hypotheses while suggesting that vagal tone is actually decreased in antisocial individuals (Mezzacappa et al., 1997; Raine, 2002).

Fewer studies have examined the relation between HR reactivity (HRR) and antisocial behavior. Lorber's (2004) review revealed that elevated HRR is associated with higher reports of conduct problems $\left(d_{+}=0.20\right)$. This effect was specific to HRR to negative stimuli $\left(d_{+}=0.26\right)$ and was not significant for reactivity to positive stimuli. In addition, whereas HRR was not associated with aggression across all studies $\left(d_{+}=0.10, n s\right)$, this effect emerged as statistically significant when the comparison was limited solely to studies that examined reactivity to negative stimuli $\left(d_{+}=0.31\right)$.

Given the relation between antisocial behavior and both low RHR and elevated HRR, an important question to be resolved is whether these two patterns of autonomic activity reflect a single underlying physiological risk factor or contribute independently to the development of antisocial behavior. Surprisingly few studies have examined both autonomic indicators in the same sample. In addition, few data are available that specifically address the psychological mechanisms hypothesized to mediate the link between physiological factors and antisocial behavior.

\section{Physiological Arousal and SIP}

SIP approaches to understanding antisocial behavior have been criticized for not adequately addressing how affective processes contribute both to deviant SIP and antisocial behavior (Crick \& Dodge, 1994; de Castro, 2004; Lemerise \& Arsenio, 2000). More specifically, the most common methods of assessing SIP (i.e., having children read, listen to, or view vignettes depicting hypothetical social interactions and then answer questions regarding the vignettes) have been critiqued for focusing on the rational and reflective components of social cognition without adequately addressing the more automatic and affective components (de Castro, 2004). A more complete understanding of the role of SIP in antisocial behavior would account for how affective processes affect each of the six stages in the Crick and Dodge (1994) reformulated model. In the early efforts to study the interplay of affective processes and SIP, experimenters used negative affecteliciting interventions such as a threatening interpersonal stressor (Dodge \& Somberg, 1987) and a frustrating video game (de Castro, Slot, Bosch, Koops, \& Veerman, 2003) and assessed changes in SIP following these interventions. Both studies found 
that evoking negative affect exacerbated hostile attributions biases in aggressive but not in nonaggressive children.

However, the relation between SIP and affective processes is likely to be bidirectional. The nature of these bidirectional effects was addressed in a model of interacting "hot" and "cool" systems that jointly determine behavioral plans (Metcalfe \& Mischel, 1999). The "hot" system is conceived as fast, emotional, simple, and reflexively responsive to unconditioned and conditioned triggers. Its activity and relative influence over behavior are greatest when stress is high. The "cool" system is slower, cognitive, complex, and reflective. Its activity and relative influence over behavior are decreased when stress is high. Distinct patterns of dysfunction in the "hot" and "cool" systems may independently contribute to the development of antisocial behavior. For example, "cool" system dysfunction may result from failure in moral socialization that leads to maladaptive beliefs regarding the appropriateness of antisocial behavior. This failure may stem from a lack of adequate learning opportunities or from an innate deficit in passiveavoidance learning that impairs the moral socialization process (Blair, 2004). On the other hand, dysfunction in the "hot" system may cause exaggerated emotional reactions to ambiguous social stimuli that bias SIP and lead to reactively antisocial behavior.

\section{The Effect of Gender}

Previous research on the relations among antisocial behaviors, SIP patterns, and ANS activity has focused mainly on male individuals, especially regarding the relation between antisocial behaviors and ANS activity. However, at least three studies have found that the relation between low RHR and antisocial behavior is also found in female individuals (Maliphant, Hume, \& Furnham, 1990; Raine, Venables, \& Mednick, 1997; Rogeness, Cepeda, Macedo, Fischer, \& Harris, 1990). In contrast, in the longitudinal sample of Moffitt and Caspi (2001), female adolescents in the adolescent-limited antisocial group ( $18 \%$ of all female participants) actually exhibited an elevated RHR (z score $=.29)$, whereas female adolescents in the life course-persistent group (1\% of all female participants) exhibited a low RHR. Thus, in the current study that assessed antisocial behavior during adolescence, it was hypothesized that low RHR would be correlated with antisocial behavior in male adolescents, and no clear hypothesis was made about female adolescents. Findings linking patterns of SIP to antisocial behavior have been found in studies that include both female and male individuals (e.g., Burks, Laird, Dodge, Pettit, \& Bates, 1999; Dodge, Bates, \& Pettit, 1990). Thus, it was hypothesized that SIP patterns would be related to antisocial behavior in both male and female adolescents.

\section{Current Study}

The participants in the current study were followed across time so that measures of antisocial behavior were collected after Grades 10,11 , and 12, and measures of SIP and cardiac activity were collected in the middle of Grade 11. The four main hypotheses of the current study were as follows: (a) deviant patterns of SIP will be correlated with antisocial behavior; (b) low RHR and elevated HRR will be correlated with antisocial behavior; (c) deviant patterns of SIP will be correlated with elevated HRR but not RHR; and (d) deviant SIP and elevated HRR will predict partially re- dundant variance in antisocial behavior (and will partially mediate the effect of each other on antisocial behavior), whereas low RHR will predict unique variance in antisocial behavior. Antisocial behavior was assessed in the years prior to and following the assessment of SIP and cardiac activity; however, in individuals of the ages studied, these patterns would not be expected to change dramatically across just a few years, and so the power of this study to detect predictors of growth in antisocial behavior across time is limited.

\section{Method}

\section{Sample}

In April of 1987 and 1988, two cohorts of participants were recruited for a longitudinal study of the development of conduct problems (see Dodge et al., 1990; Dodge, Lochman, Harnish, Bates, \& Pettit, 1997). Participants were recruited at three sites: Nashville, Tennessee, Knoxville, Tennessee, and Bloomington, Indiana. Recruitment occurred at preregistration for kindergarten in the spring before enrollment. Parents at preregistration were randomly approached by research assistants and asked if they would like to participate in the study. Approximately $15 \%$ of families did not preregister, and thus a corresponding percentage of families were recruited by phone, by mail, or during the 1 st week of school. Approximately $75 \%$ of those asked to participate agreed. The demographic characteristics of the original samples (i.e., race and socioeconomic status) were similar to those of the surrounding communities from which the samples were drawn.

Participants were assessed approximately once per year from the time the study began. The data for the current study were collected during Years 11 through 13 of the project (when participants were the ages of 16 through 18). Behavioral questionnaires were mailed to participants during each year of the current study. Completion rates for these measures ranged from $71 \%$ to $82 \%(M=76 \%)$. In addition, 411 adolescents ( $70 \%$ of the original sample) received a psychophysiology and social cognition assessment during the 11th grade; however, due to excessive artifact in some of the physiological data (e.g., extreme variability in HR data likely related to participant movement or failure to collect data due to equipment problems/experimenter error), physiological data from 14 participants were excluded from further analyses, yielding complete HR data for 386 subjects $(66 \%)$. In comparison with the original sample, those receiving the psychophysiology assessment did not significantly differ by cohort, $\chi^{2}(1, N=585)=0.70, p=.40$; gender, $\chi^{2}(1, N=585)=0.07, p=.80$; race, $\chi^{2}(1, N=585)=$ $3.02, p=.08$; socioeconomic status at study entry, $t(568)=1.86$, $p=.06$; or mother-reported externalizing behaviors at study entry, $t(565)=0.51, p=.612$. The mean Hollingshead Four-Factor Index of Social Status (Hollingshead, 1979) of the sample was $39.0(S D=13.9$, range $=6-66)$, which is in the middle-class range of the Hollingshead index. All 585 original participants are included in the current study, which includes 281 female participants (48\%), and 97 African American participants (17\%). Missing data were handled using the full information maximum likelihood estimator available in Mplus Version 4.2 (Muthén \& Muthén, 1998-2004). 


\section{Procedures}

Questionnaire measures were mailed to participants during each of the 3 years of the current study. The mailings included an informed consent document, a demographics questionnaire, and behavioral rating scales. For the current study, antisocial behavior was assessed using the Adolescent Behavior Questionnaire (ABQ; collected at ages 16-18), the Youth Self-Report (YSR; collected at age 16; Achenbach, 1991b), and the Child Behavior Checklist (CBCL; collected at age 16; Achenbach, 1991a). The ABQ was created for this study to measure the self-reported frequency of certain delinquent acts such as interpersonal violence, stealing, selling drugs, being expelled/suspended from school, and getting in trouble with the police. Adolescents were instructed to complete and return the questionnaires separately from parent-completed measures to preserve the confidentiality of their answers. The parent and adolescent each received $\$ 25$ for returning the completed questionnaires.

During the 11th-grade year, approximately 6 months after collecting the first questionnaire data, the participants were also assessed during a laboratory session. After informed consent was obtained, participants spent $1 \mathrm{hr}$ completing tasks that will be reported in future studies. In addition, participants completed the Reactive-Proactive Aggression Questionnaire (RPQ; Raine et al., 2006), which will be used in the current study. After completing these tasks, participants were given a 10-min break. After the break, the adolescents were prepared for the psychophysiology and SIP assessments. A research assistant first described the procedures and then instructed the adolescents to stand and attach self-adhesive HR sensors to the top and bottom of their breastbones. Participants were asked to attach the sensors themselves after the experimenter left the room in order to reduce the intrusiveness of the procedure. Participants were then instructed to be seated and to remain as still as possible during the rest of the procedure. The physiological data were collected and analyzed using custom hardware and software from James Long, Inc. (Canada Lake, New York). The analog electrocardiogram signal was digitized at $1000 \mathrm{~Hz}$. R waves were extracted from the electrocardiogram data off-line using an automated process that marked the rising and falling edges of the $R$ waves. The $R$ wave-to- $R$ wave interval data were then aggregated to generate an average HR in beats per minute (bpm) for each second of the procedure.

After the psychophysiology equipment was properly connected, participants were instructed to relax and remain still for a 3-min baseline period. SIP measures were then collected using two main approaches. The first approach involved videotaped vignettes followed by questions, and the second approach involved narrated stories followed by questions. The psychophysiology measures were collected continuously throughout the assessments.

The first part of the SIP assessment involved six videotaped vignettes. Each of the six video vignettes included 3 segments: the first segment in each vignette depicted an ambiguous provocation, the second segment depicted an aggressive response to the provocation, and the third segment depicted a competent, nonaggressive response to the provocation. Thus, the procedure involved 18 total segments ( 3 segments for each of the six video vignettes). The vignettes were designed to depict varied social interactions that are commonly experienced by adolescents, and the interactions were portrayed by adolescent actors. In pilot testing with normal ado- lescents, the vignettes were found to be engaging and relevant. The provocation videos in each of the six vignettes began with a social interaction and culminated in an ambiguous provocation by peers or adults directed toward a protagonist adolescent. Participants were asked to imagine themselves as the protagonists depicted in the videos. Ambiguous provocations included situations such as not being picked by peers to play in a basketball game and being confronted by a parent for coming home after curfew. Three vignettes depicted provocations that were relevant to both boys and girls and were presented to all participants. The remaining three vignettes were gender-specific for a total of nine vignettes (three shown to all participants, three shown only to female participants, and three shown only to male participants). The aggressive response segments involved verbally and affectively hostile displays toward the provocateur. Alternatively, the competent, nonaggressive response segments depicted affectively neutral responses to the provocateur.

After each of the 18 video segments were shown, questions were displayed on the video monitor as a narrator read them. Participants also had a printed copy of the questions in front of them and were asked to circle answers from a list of choices. The questions assessed the manner in which they processed the socially relevant information presented in the videos (e.g., "How likely is it that the other person meant to be mean?" "How would you want this situation to turn out?" "How good or bad of a way to act was that?").

After the six videotaped vignettes were completed, there was another 3-min baseline period. Participants were then shown six illustrations one at a time as an audiorecorded narrator read a story depicting a hypothetical provocation directed toward a protagonist. The participants were again asked to imagine being the protagonist in the story. After each story, the narrator read several questions as the text of the questions appeared on the screen. Participants were asked to follow along in their printed versions of the questions and to circle answers to the questions. The questions following the six illustrated stories were similar to the questions following the ambiguous provocation video segments.

\section{Measures}

Antisocial behavior. From the YSR and CBCL, the broadband Externalizing scale was used (YSR EXT and CBCL EXT). In addition, the YSR narrowband Aggression and Delinquency scales were used from the Age 16 assessment. From the RPQ, the Reactive Aggression (RPQ-RA) and Proactive Aggression (RPQ-PA) subscales as well as the averages of scores for these scales were used. The reliability and validity of the YSR, CBCL, and RPQ have been established in prior work (Achenbach, 1991a, 1991b; Raine et al., 2006). The ABQ is a new scale created for the Child Development Project. It was coded into five subscales: Interpersonal Violence, Stealing, Selling Drugs, Suspensions/ Expulsions From School (combined into a Trouble at School index), and Trouble With Police. An analysis of the reliability of the ABQ subscales revealed alphas of .85 for the 11 items on the Violence scale, .75 for the five items on the Stealing scale, .74 for the three items on the Trouble With Police scale, .66 for the two items on the Selling Drugs scale, and .35 for the three items on the index of Trouble at School. (We did not expect a high alpha for the Trouble at School index because some of the items are mutually 
exclusive; that is, if a youth was expelled from school, then that youth could not experience any further suspensions.) The ABQ subscales showed strong positive skew and therefore were log transformed before a mean score was calculated across the five subscales. The mean ABQ score from the Age 16 assessment (ABQ-T1) showed sufficient convergent and divergent validity. ABQ scores were positively correlated with YSR EXT, $r(437)=$ $.54, p<.001$, and with symptoms of antisocial personality disorder and conduct disorder measured 2 years later via a structured diagnostic interview, $r(402)=.51$ and $r(400)=.49$, respectively, $p s<.001$. The ABQ was also significantly related to caregiverreported antisocial behavior as assessed via CBCL EXT, $r(431)=$ $.28, p<.001$. In addition, correlations between the ABQ and the concurrently measured YSR Internalizing scale, $r(435)=.16, p<$ .01 , and the Welsh Anxiety Scale (Welsh, 1956), $r(394)=.18$, $p<.001$, were significant but notably lower than the correlations with the externalizing and antisocial measures, indicating discriminant validity. The ABQ scores from the Age 16 collection were averaged to create a Time 1 measure (ABQ-T1), and ABQ scores from the Age 17 and 18 collections were averaged to create a mean Time 2 score (ABQ-T2).

SIP. SIP was assessed after each of the 18 video segments (six ambiguous provocation segments, six aggressive response segments, and six nonaggressive response segments) and after each of the six narrated stories, which also depicted ambiguous provocations. Participants' answers to these questions were used to create four variables that reflected Steps 2 through 5 of the reformulated SIP model of Crick and Dodge (1994). The first variable, hostile attributions (HA; $\alpha=.73$ ), refers to the interpretation step of the model and was based on questions regarding the perceived intent of the provocateurs in the provocation videos and the narrated stories (i.e., whether the provocateur intended to be mean to the protagonist). Higher scores indicated higher levels of hostile intent attributions to the provocateurs depicted in the videos and narrated stories. The second variable, self-defense goal orientation (SDG; $\alpha=.80$ ), assessed the goal clarification step of the SIP model. This measure was based on a question that asked participants to choose between two goals for resolving the provocations: wanting to be respected or wanting to be liked. This score reflected the percentage of times that participants chose "respect" across the six video provocations segments and the six narrated stories. Higher scores on this measure reflect a greater likelihood to formulate social goals in terms of guarding against interpersonal threats rather than fostering relationships. The third variable, accessing aggression ( $\mathrm{AA} ; \alpha=.75$ ), assessed the response access and construction step of the SIP model. This measure was based on a question that asked participants to choose between an aggressive and a nonaggressive response to the provocations. This score reflected the percentage of times that participants chose aggressive responses across the six provocation videos and six narrated stories. The fourth measure, positively evaluating aggression (PEA; $\alpha=.89$ ), assessed aspects of response evaluation and decision. This measure was based on four questions that followed each aggressive response video segment. The questions concerned how good or bad the aggressive response was, how well one could achieve interpersonal goals by responding this way, how well one could achieve instrumental goals by acting this way, and how the participants would feel about themselves if they acted this way. These four variables were averaged to create the new measure.
Higher scores indicated a more positive evaluation of aggressive responses to the ambiguous provocations. As the results will describe, the SDG variable did not load significantly on a latent construct of SIP and was dropped from other analyses. The other three SIP variables were analyzed.

Cardiac activity. The psychophysiological data were used to create resting RHR and HRR scores. Before calculating these measures, we examined second-by-second HR values for each participant for artifact. We identified intrasubject artifacts for second-by-second HR by using the criteria of 2.5 times the standard deviation above and below an individual's mean HR across the procedure. In addition, physiologically unlikely values of HR (below $30 \mathrm{bpm}$ and above $150 \mathrm{bpm}$ ) were also coded as artifact. The average amount of intrasubject artifact was $1.8 \%$. Individuals who were extreme outliers in terms of artifactual data (i.e., the percentage of artifactual data was more than three times the interquartile range above the third quartile [ $>6.5 \%]$ ) were not used in the analyses. In addition, individuals whose mean RHR was both outside the normal clinical range for their age (55-95 bpm for male participants and 60-100 bpm for female participants; Behrman, Kliegman, \& Jenson, 2000) and were identified as statistical outliers (i.e., $>1.5$ times the interquartile range below or above the first and third quartiles, respectively) were also not used in the present analyses. Overall, HR data were available for 386 participants.

RHR was calculated by taking the mean of the second-bysecond HR during the 173-s baseline period at the beginning of the procedure. HRR was computed from the cross-time HR trajectories. Figure 1 depicts the mean HR trajectories in response to the provocation stimuli. Arrows depict where the provocation video started and ended within each segment. The mean HR trajectories show a gradual decline while the provocation story was being presented (reflecting attention to the provocation stimulus) and a sharp increase following the provocation itself while questions were asked. The overall pattern was interpreted as initial attentiveness to the provocation video (with attention indicated by a decline in HR) followed by a sharp reactivity to the provocation itself and the questions asked afterward. The HRR measure was calculated by subtracting the $\mathrm{HR}$ at the end of each provocation video segment from the maximum HR obtained during the 20-s period immediately following the end of each video. The HRR score reflects the average increase across the six provocation segments $(\alpha=.81)$. It is noted that this score was significantly correlated, $r(384)=.61, p<.001$, with the attention-to-provocation score computed as the difference in HR from the beginning of the provocation vignette to the end of the vignette. We used the HRR score for the data analysis reported here; however, we obtained similar findings using the attention-to-provocation score. Thus, findings should be interpreted as reflecting a pattern of reactivity to the entire provocation stimulus.

\section{Statistical Approach}

The main study hypotheses were evaluated with structural equation models (SEM) that were estimated with Mplus Version 4.2. Missing data were handled with full information maximum likelihood estimation as implemented in Mplus. 
Provocation Vignettes

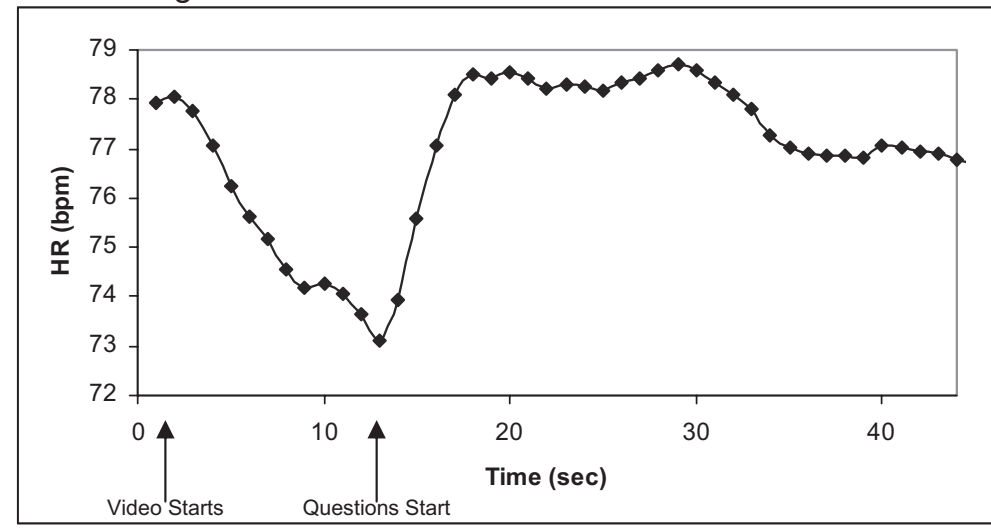

Figure 1. Mean heart rate (HR) trajectories during presentation of provocation video segments.

\section{Results}

\section{Summary of the Main Study Measures}

Table 1 contains the means and standard deviations for the behavior, SIP, and cardiac measures separately for male and female participants and the mean comparisons by gender for all of these measures. Mean gender contrasts were conducted with $t$ tests in SPSS Version 14.0. Male participants, relative to female participants, reported significantly higher levels of antisocial behavior on the following measures: ABQ-T1, ABQ-T2, RPQ-RA, and RPQ-PA. In addition, male participants exhibited significantly

Table 1

Descriptive Statistics for Study Measures

\begin{tabular}{lcccccc}
\hline & \multicolumn{3}{c}{} & \multicolumn{3}{c}{$\begin{array}{c}\text { Female } \\
\text { participants }\end{array}$} \\
\cline { 2 - 3 } \multicolumn{1}{c}{ Measure } & $M$ & $S D$ & & $M$ & $S D$ & \\
\hline ABQ-T1 & 22.00 & 42.80 & & 9.57 & 17.12 & .000 \\
ABQ-T2 & 12.90 & 18.4 & & 5.69 & 12.41 & .000 \\
YSR EXT & 11.70 & 7.57 & & 11.49 & 7.39 & $n s$ \\
RPQ-RA & 1.34 & 0.70 & & 1.06 & 0.63 & .000 \\
RPQ-PA & 0.47 & 0.50 & & 0.23 & 0.33 & .000 \\
CBCL EXT & 8.35 & 7.13 & & 8.22 & 8.28 & $n s$ \\
HA & 2.45 & 0.46 & & 2.25 & 0.50 & .000 \\
SDG & 0.64 & 0.25 & & 0.65 & 0.25 & $n s$ \\
AA & 0.10 & 0.16 & & 0.04 & 0.10 & .000 \\
PEA & 2.07 & 0.39 & & 1.89 & 0.38 & .000 \\
RHR & 73.00 & 10.60 & & 75.53 & 11.51 & .02 \\
HRR & 14.70 & 5.54 & 12.69 & 4.72 & .000 \\
\hline
\end{tabular}

Note. Means for male and female participants were compared with twotailed $t$ tests. ABQ-T1 $=$ Adolescent Behavior Questionnaire scores in Grade 10; $\mathrm{ABQ}-\mathrm{T} 2$ = mean of $\mathrm{ABQ}$ scores in Grades 11 and 12; YSR$\mathrm{EXT}=$ Youth Self-Report Externalizing scale (Achenbach, 1991b); RPQRA $=$ Reactive-Proactive Aggression Questionnaire Reactive Aggression subscale (Raine et al., 2006); RPQ-PA = Reactive-Proactive Aggression Questionnaire Proactive Aggression subscale (Raine et al., 2006); CBCLEXT $=$ Child Behavior Checklist Externalizing scale (Achenbach, 1991a); $\mathrm{HA}=$ hostile attributions; SDG = self-defense goal orientation; AA = accessing aggression; PEA = positively evaluating aggression; RHR = resting heart rate; HRR = heart rate reactivity to the ambiguous provocation videos. more deviant SIP as measured by HA, AA, and PEA. Finally, male participants exhibited significantly lower RHR and higher HRR. Overall, relative to female participants, male participants exhibited higher levels of antisocial behavior and were more likely to exhibit patterns of SIP and cardiac physiology that have been associated with antisocial behavior in past studies.

Table 2 depicts the bivariate correlations between all study measures separately for male and female participants (below and above the diagonal, respectively), with significant moderation by gender noted in bold font. Gender differences in bivariate correlations were tested using the Fisher's $z^{\prime}$ transformation (J. Cohen $\&$ Cohen, 1983). Although the main study hypotheses are evaluated below using an SEM approach, the patterns of bivariate correlations are generally consistent with the main study hypotheses. Antisocial behavior in both male and female participants was associated with deviant SIP. The HA, AA, and PEA measures exhibited significant correlations with multiple measures of antisocial behavior, including general antisocial behavior (ABQ-T1 and YSR EXT) as well as reactive and proactive aggression (RPQ-RA and RPQ-PA).

In addition, antisocial behavior exhibited the predicted negative correlation with RHR for male participants (significant for RPQ-PA and marginal for RPQ-RA). However, for female participants, RHR was not significantly negatively correlated with antisocial behavior; rather, it tended to be positively related to antisocial behavior (significant for CBCL EXT and marginal for ABQ-T1).

Antisocial behavior was also significantly positively correlated with HRR, although again the finding was moderated by gender. For male participants, HRR was positively correlated with ABQT1, YSR EXT, and RPQ-RA and was marginally correlated with the other measures of antisocial behavior (ABQ-T2, RPQ-PA, and CBCL EXT). For female participants, HRR was only marginally positively correlated with ABQ-T1.

Deviant SIP was also related to elevated HRR for both male and female participants. For male participants, HRR was significantly related to AA and PEA, whereas as for female participants, HRR was significantly related to SDG. In addition, for female participants, RHR was also positively related to both AA and PEA. 
Table 2

Correlations Among Study Measures by Gender

\begin{tabular}{|c|c|c|c|c|c|c|c|c|c|c|c|c|}
\hline Measure & 1 & 2 & 3 & 4 & 5 & 6 & 7 & 8 & 9 & 10 & 11 & 12 \\
\hline 1. ABQ-T1 & - & $.58^{* * * *}$ & $.50^{* * * *}$ & $.43^{* * * *}$ & $.50^{* * * *}$ & $.43^{* * *}$ & $.19^{* * *}$ & .01 & $.23^{* *}$ & $.21^{* *}$ & $.13^{\dagger}$ & $.14^{\dagger}$ \\
\hline 2. ABQ-T2 & $.67^{* * * *}$ & - & $.47^{* * * *}$ & $.31^{* * * *}$ & $.54^{* * * *}$ & $.42^{* * * *}$ & $21^{* * *}$ & .09 & $.27^{* * * *}$ & $.26^{* * *}$ & .08 & .01 \\
\hline 3. YSR EXT & $.55^{\text {*** }}$ & $.52^{* * *}$ & - & $.50^{\text {**** }}$ & $.51^{* * * *}$ & $.35^{\text {**** }}$ & .12 & -.04 & $.16^{*}$ & $.18^{*}$ & .06 & -.04 \\
\hline 4. RPQ-RA & $.53^{* * *}$ & $.42^{* * * *}$ & $.60^{* * * *}$ & - & $.59^{\text {**** }}$ & $26^{\text {**** }}$ & $.19^{* * *}$ & -.03 & $.24^{* *}$ & $.22^{*}$ & .01 & -.05 \\
\hline 5. RPQ-PA & $.63^{* * * *}$ & $.51^{* * * *}$ & $.56^{* * * *}$ & $.63^{* * * *}$ & - & $.26^{* * * *}$ & $.30^{* * * *}$ & .07 & $.24^{* *}$ & $.33^{* * *}$ & .11 & .09 \\
\hline 6. CBCL EXT & $.35^{* * *}$ & $.41^{* * * *}$ & $.41^{* * * * *}$ & $.23^{* *}$ & $.23^{* *}$ & - & -.02 & .00 & $21^{* *}$ & .07 & $.18^{*}$ & -.00 \\
\hline 7. HA & $.15^{*}$ & $.18^{* *}$ & $.18^{*}$ & $.17^{*}$ & $.19^{* * *}$ & .07 & - & .06 & $.32^{* * * *}$ & $.56^{* * * *}$ & .03 & .11 \\
\hline 8. SDG & $.20^{* * *}$ & .09 & .09 & $.21^{* *}$ & $23^{* *}$ & $.15^{*}$ & -.02 & - & .06 & .07 & .06 & $.17^{*}$ \\
\hline 9. $\mathrm{AA}$ & $.44^{* * *}$ & $.47^{* * *}$ & $.35^{* * * *}$ & $.44^{* * * *}$ & $.47^{* * * *}$ & $.22^{* *}$ & $.38^{* * * *}$ & .10 & - & $.53^{* * * *}$ & $.17^{*}$ & -.03 \\
\hline 10. PEA & $.46^{* * * *}$ & $.49^{* * *}$ & $.48^{* * * *}$ & $.50^{* * * *}$ &. $\mathbf{5 0}^{* * * *}$ & $.31^{* * * *}$ & $.40^{* * * *}$ & $.16^{*}$ & $.63^{* * * *}$ & - & $.18^{*}$ & -.03 \\
\hline 11. RHR & -.10 & -.00 & -.09 & $-.12^{\dagger}$ & $-.15^{*}$ & .00 & -.02 & .00 & .05 & .09 & - & -.12 \\
\hline 12. HRR & $.15^{*}$ & $.13^{\dagger}$ & $.20^{* * *}$ & $.18^{*}$ & $.14^{\dagger}$ & $.13^{\dagger}$ & $-.12^{\dagger}$ & $.13^{\dagger}$ & $.19^{* * *}$ & $.16^{*}$ & $-.12^{\dagger}$ & - \\
\hline
\end{tabular}

Note. Bivariate correlations for female participants are above the diagonal. Correlations for male participants are below the diagonal. Correlations in bold indicate that the correlations for male and female participants were significantly different based on a two-tailed $z$ test $(p<.05)$ using the Fisher's $z^{\prime}$ transformation. ABQ-T1 = Adolescent Behavior Questionnaire scores in Grade 10; ABQ-T2 = mean of ABQ scores in Grades 11 and 12; YSR-EXT $=$ Youth Self-Report Externalizing scale (Achenbach, 1991b); RPQ-RA = Reactive-Proactive Aggression Questionnaire Reactive Aggression subscale (Raine et al., 2006); RPQ-PA = RPQ Proactive Aggression subscale (Raine et al., 2006); CBCL-EXT = Child Behavior Checklist Externalizing scale (Achenbach, 1991a); HA = hostile attributions; SDG = self-defense goal orientation; AA = accessing aggression; PEA = positively evaluating aggression; RHR = resting heart rate; $\mathrm{HRR}=$ heart rate reactivity to the ambiguous provocation videos.

${ }^{\dagger} p<.10 .{ }^{*} p<.05 .{ }^{* *} p<.01 .^{* * *} p<.001$.

\section{Evaluating the Main Study Hypotheses}

The general SEM model that was used to evaluate the main study hypotheses is depicted in Figure 2. As shown, the model includes latent constructs for both deviant SIP and antisocial behavior, while RHR and HRR are included as observed variables. In this model, antisocial behavior is regressed on SIP, RHR, and HRR. In addition, SIP is regressed on both RHR and HRR to allow for testing of the indirect effects of the cardiac measures on antisocial behavior via their effect on SIP. Several different versions of the main model were evaluated to examine whether the coordination of SIP and cardiac measures in explaining antisocial behavior depends on the type of antisocial behavior that is considered (general antisocial behavior, reactive violence, and nonreactive delinquency).

Evaluation of the measurement model. The fit of the SIP and three antisocial latent constructs were examined in separate confirmatory factor analyses (CFAs). The initial SIP model included all four SIP measures as indicators, and all loadings were constrained to be equal across gender. The fit of this model was not adequate as indicated by a root mean square error of approxima-

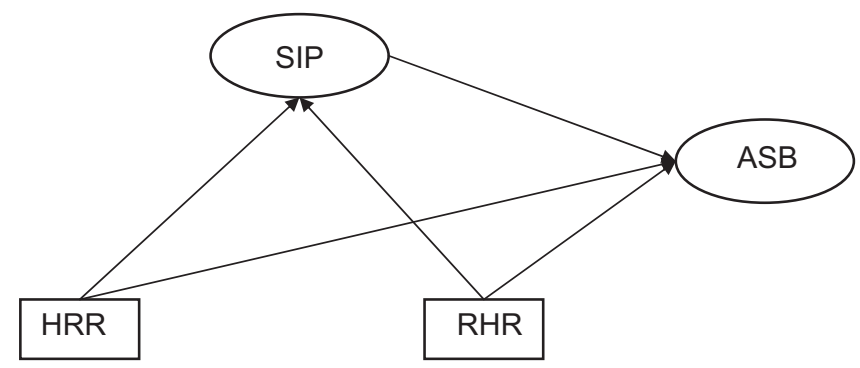

Figure 2. Example structural equation model. HRR $=$ heart rate reactivity; $\mathrm{SIP}=$ social information processing; $\mathrm{RHR}=$ resting heart rate; $\mathrm{ASB}=$ antisocial behavior construct that varies across models. tion (RMSEA) of .10. The fit of the model was significantly improved by relaxing the gender invariance constraint, $\Delta \chi^{2}(3, N=$ $411)=27.90, p<.001$. However, the SDG measure did not load significantly on the SIP construct for male or female participants. Therefore, this indicator was dropped, and the model was reestimated. The final SIP model exhibited excellent fit, $\chi^{2}(2, N=$ $411)=0.001, n s$, comparative fit index $(\mathrm{CFI})=1.00$, RMSEA $<$ .001. The factor loading for HA was constrained to equal 1 to allow model estimation. The remaining factor loadings for male participants (AA, $\beta=0.54, S E=0.09, p<.001$; and PEA, $\beta=$ 1.43, $S E=0.24, \mathrm{p}<.001)$ and female participants $(\mathrm{AA}, \beta=0.19$, $S E=0.03, p<.001 ;$ and PEA, $\beta=1.26, S E=0.24, p<.001)$ were significant.

The general antisocial behavior latent construct had three indicators: ABQ-T1, YSR EXT, and the average of the scores from the RPQ-RA and RPQ-PA scales (RPQ-AVG). The CFA indicated that the overall fit was adequate, $\chi^{2}(4, N=477)=4.36, n s, \mathrm{CFI}=$ 1.00 , RMSEA $=.02$. The factor loading for YSR EXT was constrained to equal 1 . The loadings for both RPQ-AVG, $\beta=$ $0.44, S E=0.03, p<.001$, and ABQ-T1, $\beta=0.98, S E=0.08$, $p<.001$, were significant.

The reactive violence latent construct had three indicators: RPQ-RA, the YSR Aggression scale, and the Violence subscale from ABQ-T1. The CFA indicated that the model fit adequately, $\chi^{2}(4, N=477)=4.73, n s, \mathrm{CFI}=1.00, \mathrm{RMSEA}=.03$. The factor loading for the YSR Aggression scale was constrained to equal 1. The loadings for the ABQ-T1 Violence subscale, $\beta=1.64, S E=$ $0.17, p<.001$, and RPQ-RA, $\beta=0.47, S E=0.05, p<.001$, were significant.

The nonreactive delinquency construct also had three indicators: the YSR Delinquency scale, the mean of the ABQ subscales except for the Violence subscale, and the RPQ-PA. The fit of the CFA was adequate, $\chi^{2}(4, N=477)=4.62, n s, \mathrm{CFI}=1.00$, RMSEA $=$ .03. The factor loading for the YSR Delinquency scale was constrained to equal 1 . The loadings for the average of the ABQ-T1 
Delinquency subscales, $\beta=1.03, S E=0.10, p<.001$, and for RPQ-PA, $\beta=0.44, S E=0.04, p<.001$, were significant.

Evaluation of the structural models. In the first model, the coordination of SIP and cardiac measures in explaining general antisocial behavior was examined. The model was first examined with all structural paths constrained to be equal for male and female participants. The overall model fit was adequate, $\chi^{2}(43$, $N=480)=92.10, p<.001$, CFI $=0.94$, RMSEA $=.07$. An omnibus test of gender moderation was conducted by freeing all structural paths across groups, which resulted in a significant improvement in model fit, $\Delta \chi^{2}(5, N=480)=33.43, p<.001$. Follow-up analyses in which each of the five structural paths were individually freed showed that freeing the paths from RHR to antisocial behavior, $\Delta \chi^{2}(1, N=480)=6.40, p<.05$, and from SIP to antisocial behavior, $\Delta \chi^{2}(1, N=480)=20.35, p<.001$, both significantly improved the overall model. In the final model shown in Figure 3, only these two paths were freed. The overall fit of the final model is acceptable, $\chi^{2}(41, N=480)=61.37, p<.05$, $\mathrm{CFI}=0.98$, RMSEA $=.05$. For the general antisocial behavior latent construct, $R^{2}=.60$ and $R^{2}=.17$ for male and female participants, respectively.

For male participants, the results indicate that deviant SIP was significantly positively related to general antisocial behavior, $\beta=$ 1.92, $S E=0.34, p<.001$, whereas RHR was significantly negatively related to general antisocial behavior, $\beta=-0.01, S E=$ $0.003, p<.001$. In addition, both RHR, $\beta=0.003, S E=0.001$, $p<.05$, and HRR, $\beta=0.006, S E=0.003, p<.05$, were significantly positively related to deviant SIP. The significance of the indirect effects of the cardiac measures on general antisocial behavior via SIP was evaluated using the asymmetric confidence interval approach as recommended by MacKinnon and colleagues (MacKinnon, Lockwood, Hoffman, West, \& Sheets, 2002). The indirect effects of RHR, $\beta_{\mathrm{IND}}=.006, S E=.002, p<.05$, and HRR, $\beta_{\text {IND }}=.006, S E=.002, p<.05$, on the general antisocial behavior construct were both significant, indicating that deviant SIP mediated the effects of these autonomic variables on antisocial behavior.

For female participants, the main difference in the model results was that only deviant SIP was significantly related to general antisocial behavior, $\beta=0.54, S E=0.13, p<.001$. Similar to the findings among male participants, the indirect effects from RHR, $\beta_{\text {IND }}=.002, S E=.001, p<.05$, and HRR, $\beta_{\text {IND }}=.003, S E=$ $.002, p<.05$, to the antisocial behavior construct were both significant, indicating that deviant SIP mediated the effects of these autonomic variables on antisocial behavior. Thus, the findings are largely consistent with study hypotheses.

To test whether different types of antisocial behavior exhibit different patterns of relations to social cognition and physiological arousal, the model in Figure 3 was applied separately to the reactive violence and nonreactive delinquency constructs. The results for the model explaining reactive violence are presented in Figure 4. The overall fit of the model was acceptable, $\chi^{2}(41, N=$ $480)=73.62, p<.05$, CFI $=0.96$, RMSEA $=.06$. For the reactive violence latent construct, $R^{2}=.56$ and $R^{2}=.14$ for male and female participants, respectively. For both male and female participants, the same pattern of significant direct effects was observed as was found for the general antisocial construct. For male participants, the direct effects of SIP, $\beta=1.81$, $S E=0.34$, $p<.001$, and RHR, $\beta=-0.01, S E=0.003, p<.001$, on the reactive violence construct were significant. In addition, the indirect effects from RHR, $\beta_{\mathrm{IND}}=.006, S E=.002, p<.05$, and HRR, $\beta_{\text {IND }}=.010, S E=.005, p<.05$, on reactive violence were also significant. For female participants, the direct effect of SIP, $\beta=0.49, S E=0.14, p<.001$, and the indirect effects of RHR,
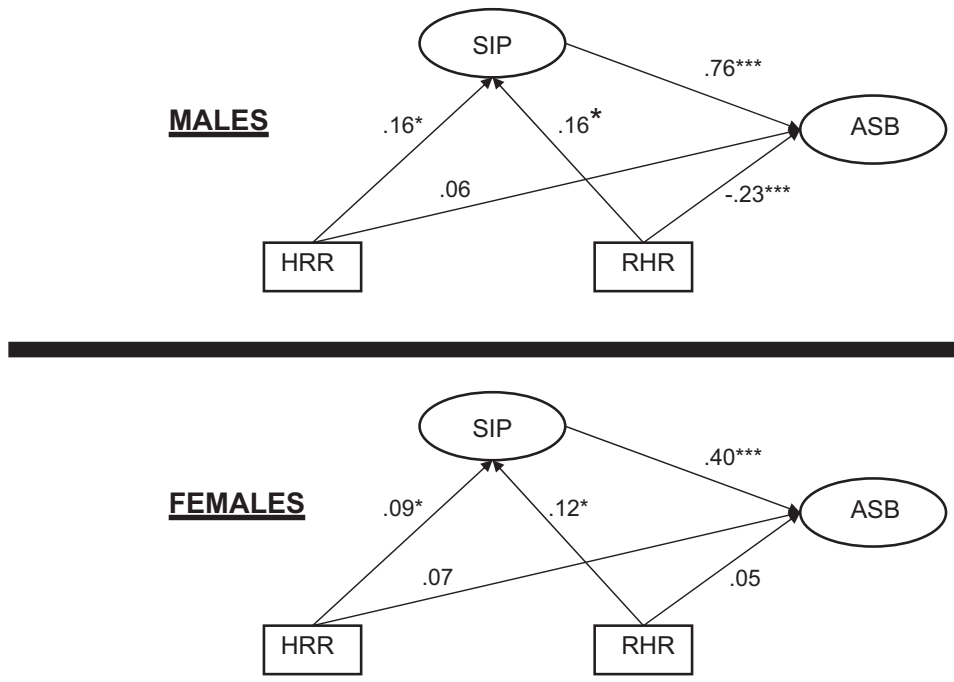

Figure 3. Model explaining general antisocial behavior. Standardized path coefficients are presented. HRR $=$ heart rate reactivity; $\mathrm{SIP}=$ social information processing; $\mathrm{RHR}=$ resting heart rate; $\mathrm{ASB}=$ general antisocial behavior construct. ${ }^{*} p<.05 .{ }^{* * *} p<.001$. 
$\mathrm{X}^{2}(41, N=480)=73.62, p<.01$

$\mathrm{CFI}=.96 ; \mathrm{RMSEA}=.058$
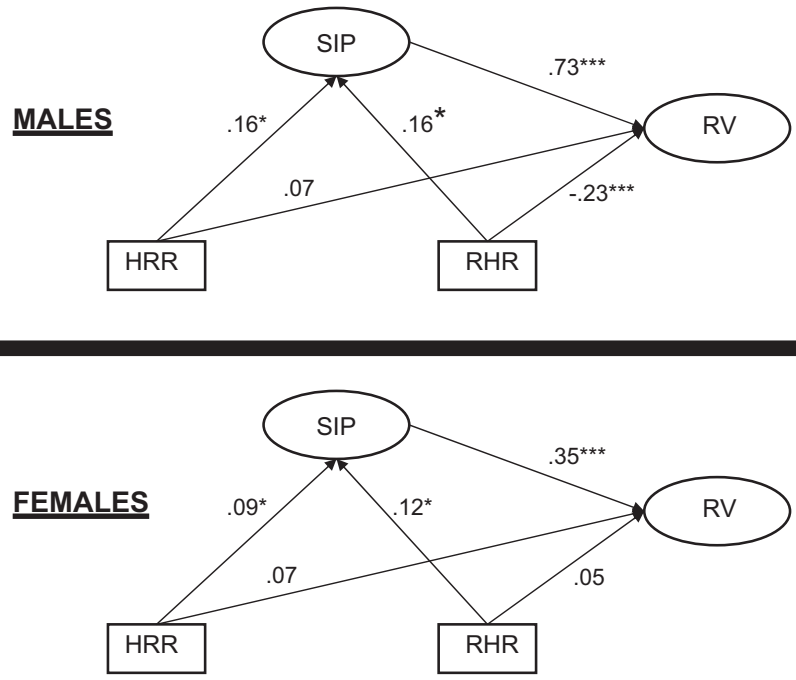

Figure 4. Model explaining reactive violence. Standardized path coefficients are presented. HRR $=$ heart rate reactivity; SIP = social information processing; RHR = resting heart rate; $\mathrm{RV}=$ reactive violence construct.

${ }^{*} p<.05 .{ }^{* * *} p<.001$.

$\beta_{\text {IND }}=.002, S E=.001, p<.05$, and HRR, $\beta_{\text {IND }}=.003, S E=.001$, $p<.05$, on reactive violence were significant. Thus, the pattern of significant findings is identical to what was found for general antisocial behavior and is largely consistent with the study hypotheses.

The model was also estimated using the nonreactive delinquency construct as the primary outcome. The results for this model are presented in Figure 5. The model fit was acceptable, $\chi^{2}(41, N=480)=61.37, p<.05, \mathrm{CFI}=0.97, \mathrm{RMSEA}=.05$. $R^{2}=.57$ and $R^{2}=.20$ for male and female participants, respectively. The same pattern of direct effects was again observed. For male participants, the direct effects of SIP, $\beta=1.71, S E=0.31, p<$ .001 , and RHR, $\beta=-0.008, S E=0.003, p<.01$, on nonreactive

$\mathrm{X}^{2}(41, N=480)=61.37, p<.05$

$\mathrm{CFI}=.97 ; \mathrm{RMSEA}=.045$
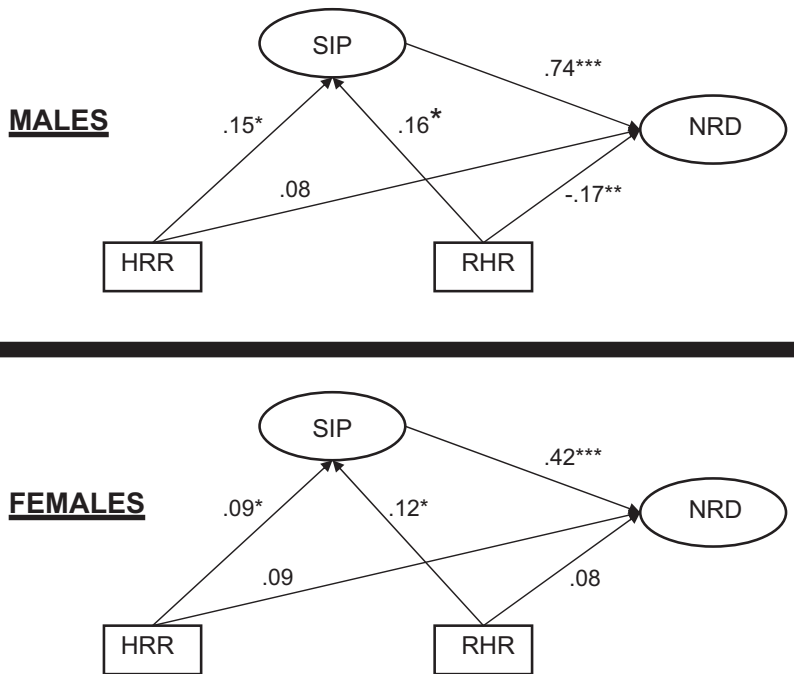

Figure 5. Model explaining nonreactive delinquency. Standardized path coefficients are presented. HRR = heart rate reactivity; SIP = social information processing; RHR $=$ resting heart rate; $\mathrm{NRD}=$ nonreactive delinquency construct.

${ }^{*} p<.05 .{ }^{* *} p<.01 .{ }^{* * *} p<.001$. 
delinquency were significant. In addition, the indirect effects of RHR, $\beta_{\text {IND }}=0.006, S E=.002, p<.05$, and HRR, $\beta_{\text {IND }}=0.010, S E=$ $.005, p<.05$, on nonreactive delinquency were also significant. For female participants, the direct of effect of SIP on nonreactive delinquency was significant, $\beta=0.50, S E=0.12, p<.001$, and the indirect effects of RHR, $\beta_{\mathrm{IND}}=0.002, S E=.001, p<.05$, and HRR, $\beta_{\text {IND }}=.006, S E=.003, p<.05$, on nonreactive delinquency were significant. Again, the pattern of significant findings is identical to what was found for both general antisocial behavior and reactive violence, suggesting that the model proposed in the current study does not vary by the type of antisocial behavior considered as far as the types were assessed in the current study.

To test whether the proposed model also explains variance in caregiver-reported antisocial behavior, the model was reestimated with CBCL EXT as the primary outcome. The results of this model are presented in Figure 6. The overall model exhibited adequate fit, $\chi^{2}(17, N=469)=39.04, p<.01, \mathrm{CFI}=0.93, \mathrm{RMSEA}=.07$. $R^{2}=.09$ for male participants and $R^{2}=.04$ for female participants. The main differences from the results from the models using self-report measures is that RHR was not significantly related to CBCL EXT for male participants, whereas it exhibited a significant positive effect for female participants, $\beta=0.13, S E=0.06$, $p<.05$. In addition, SIP emerged as significant for male participants, $\beta=10.12, S E=2.98, p<.001$, but not for female participants. The indirect effects of RHR, $\beta_{\mathrm{IND}}=0.03, S E=.02$, $p<.05$, and HRR, $\beta_{\text {IND }}=0.06, S E=.03, p<.05$, via SIP were significant for male participants only.

To test whether the SIP and cardiac measures would continue to explain variance in the change in antisocial behavior, a final model was estimated that included ABQ-T1 and ABQ-T2 as dependent measures. The results of this model are presented in Figure 7. The overall model fit was acceptable, $\chi^{2}(22, N=485)=39.07, p<$
$.05, \mathrm{CFI}=0.97, \mathrm{RMSEA}=.06$. For ABQ-T1, $R^{2}=.35$ for male participants and $R^{2}=.10$ for female participants. For ABQ-T2, $R^{2}=.64$ for male participants and $R^{2}=.49$ for female participants. In this model, the main parameters of interest were the direct and indirect effects on $\mathrm{ABQ}-\mathrm{T} 2$. For male participants, the direct effects of ABQ-T1, $\beta=0.45, S E=0.05, p<.001$, and SIP on ABQ-T2, $\beta=1.03, S E=0.27, p<.001$, were significant. In addition, the indirect effects of RHR, $\beta_{\mathrm{IND}}=0.003, S E=0.001$, $p<.05$, and HRR, $\beta_{\text {IND }}=0.006, S E=0.003, p<.05$, were also significant. For female participants, only the direct effect of ABQ$\mathrm{T} 1, \beta=0.60, S E=0.05, p<.001$, was significant. Therefore, this model indicates that deviant SIP explained the change in antisocial behavior over the short time period observed in the current study for male but not for female participants.

Evaluating alternative models. The manner in which data were collected for the current study does not allow us to draw firm conclusions regarding directions of causality. Therefore, other possible models were considered to explain the observed relations among study measures. The first alternate model involved reversing the direction of the direct effect of RHR and HRR on SIP and evaluating whether the cardiac measures mediated the relation between SIP and general antisocial behavior. This model used the same pattern of gender constraints described above. The overall fit of this model was acceptable, $\chi^{2}(43, N=480)=69.28, p<.01$, $\mathrm{CFI}=0.97, \mathrm{RMSEA}=.05$. In this model, the direct effect of SIP on antisocial behavior was significant even when RHR was included as a possible mediator, $\beta=6.13, S E=2.45, p<.05$, but the effect of SIP on antisocial behavior was not significant when HRR was included as a mediator. For male participants, the indirect effect of SIP on antisocial behavior via RHR was significant and negative, $\beta_{\text {IND }}=-0.07, S E=0.03, p<.05$, whereas the indirect effect of SIP on antisocial behavior via HRR was not

$\mathrm{X}^{2}(17, N=469)=39.04, p<.01$

$\mathrm{CFI}=.94 ; \mathrm{RMSEA}=.074$
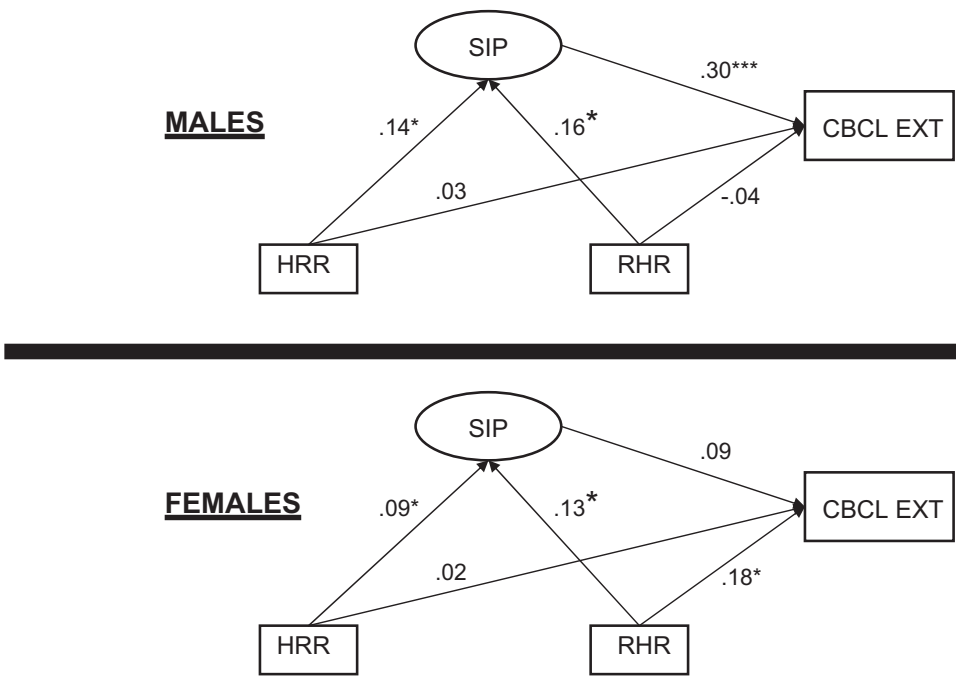

Figure 6. Model explaining Child Behavior Checklist (CBCL; Achenbach, 1991a) Externalizing scale scores. Standardized path coefficients are presented. HRR = heart rate reactivity; SIP = social information processing; $\mathrm{RHR}=$ resting heart rate; CBCL EXT $=$ CBCL Externalizing scale. ${ }^{*} p<.05 .{ }^{* * *} p<.001$. 
$X(25, N=304)=39.07, p<.05$

$\mathrm{CFI}=.97 ; \mathrm{RMSEA}=.057$
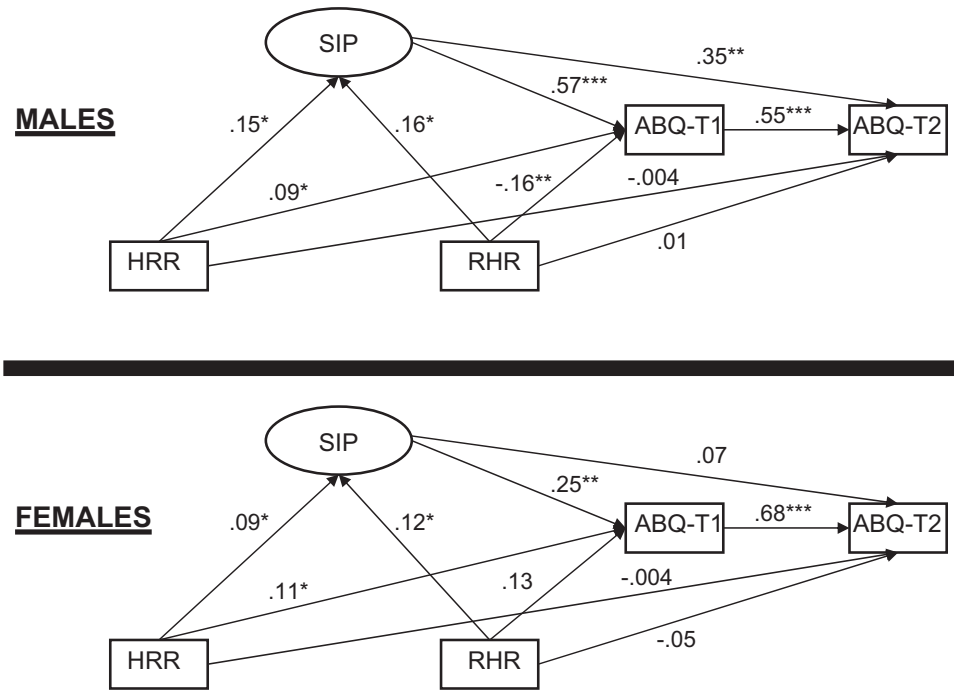

Figure 7. Model explaining the Adolescent Behavior Questionnaire (ABQ) scores from the Age 17 and 18 collections (Time 2 [T2]) controlling for ABQ scores from the Age 16 assessment (Time 1 [T1]). Standardized path coefficients are presented. ${ }^{*} p<.05 .{ }^{* * *} p<.01 .{ }^{* * * *} p<.001$

significant. For female participants, the indirect effects of SIP via RHR and HRR were not significant. Thus, although the overall model adequately fits the data, the pattern of findings suggests that there is less evidence to support a model positing that HRR mediates the effect of SIP than was found for the reverse model in which SIP mediated the effect of HRR.

A final model was considered in which a new latent construct was created to represent an antisocial tendency more broadly defined. The indicators of this construct included the indicators of the general antisocial behavior construct (YSR EXT, ABQ-T1, and RPQ-AVG) plus the indicators of the SIP construct (HA, AA, and PEA). In this model, RHR and HRR were both regressed on this construct. The model was initially estimated with both regression parameters constrained across gender. The model was significantly improved by freeing the direct effect of the antisocial construct on RHR, $\Delta \chi^{2}(1$, $N=480)=5.09, p<.05$; therefore, in the final model this constraint was relaxed. Nonetheless, the overall fit of this model was poor, $\chi^{2}(49, N=480)=241.44, p<.001, \mathrm{CFI}=0.78, \mathrm{RMSEA}=.13$. An examination of the loadings on the antisociality construct revealed that all of the factor loadings were significant. The direct effect of antisociality on RHR was not significant for either male or female participants. The direct effect of antisociality on HRR was significant, $\beta=1.76, S E=0.65, p<.01$. Overall, the fit of this model was less optimal than the fit of the hypothesized model.

\section{Discussion}

\section{A Multiprocess Model of Antisocial Behavior in Male Adolescents}

The findings of this study are consistent with a multiprocess model of antisocial behavior involving both cardiac and social- cognitive components. Two physiological constructs (RHR and HRR) predict antisocial behavior, but their mechanisms differ. Among male adolescents, low RHR had a direct effect on antisocial behavior that was not mediated by SIP patterns. Among male and female adolescents, elevated HRR and elevated RHR exhibited indirect effects on antisocial behavior that were mediated by deviant SIP. In addition to the physiological components, deviant SIP patterns further contributed to antisocial behavior for both male and female individuals. The findings in the current study appear to be consistent across subtypes of antisocial behavior.

$R H R$. Tonic cardiac activity as indexed by RHR is a highly heritable trait and may partly account for the intergenerational transmission of antisocial behavior (Raine, 2002). The findings from the current study are consistent with previous work showing that low RHR is associated with antisocial behavior in male individuals (Lorber, 2004; Ortiz \& Raine, 2004). Low RHR has been proposed as a marker of trait fearlessness. The most direct evidence for this hypothesis comes from work in children showing that uninhibited temperament is associated with low RHR (Scarpa, Raine, Venables, \& Mednick, 1997). Over the course of development, relative fearlessness in the face of punishment and retaliation for antisocial behavior may interfere with avoidance learning and the process of moral socialization.

The finding that elevated RHR exerted a positive indirect effect on antisocial behavior via its effect on deviant SIP suggests that the relation between RHR and antisocial behavior may be more complicated than previously realized. This positive indirect effect may reflect that a subgroup of antisocial youth exhibits a tonic level of physiological hyperarousal perhaps triggered by mild environmental stressors such as participating in the experimental task. And although the indirect effect of RHR was not moderated 
by gender, the effect appeared to be particularly relevant for female participants for whom RHR exhibited significant bivariate correlations with both deviant SIP and antisocial behavior.

HRR to provocations. The second component of the multiprocess model of antisocial behavior is heightened cardiac reactivity to socially provocative stimuli, as measured in the current study by HR changes in response to the videotaped vignettes depicting ambiguous social provocations. HRR has been shown to be relatively stable over time (S. Cohen \& Hamrick, 2003), only partly heritable (Lensvelt-Mulders \& Hettema, 2001), and related to trait hostility (Suarez, Kuhn, Schanberg, Williams, \& Zimmermann, 1998). However, increased HRR to aversive stimuli can also be learned, as has been shown in a twin study of posttraumatic stress disorder (Pitman et al., 2006).

The pattern of HRR observed in the current study involved both increased HR immediately following the presentation of a provocation that participants imagined happening to themselves and decreased HR immediately prior to the provocation, when participants were expecting a provocation to occur. Data analyses indicated that both responses correlated with increased antisocial behavior and accounted for similar variance. This indirect effect of HRR on antisocial behavior remained significant even when controlling for RHR, indicating that multiple physiological processes must be included in a comprehensive model of antisocial behavior. This finding is consistent with the work of Lorber (2004), who found that across studies, HRR to stimuli with a negative valence was particularly linked to antisocial behavior.

Whether these two cardiac processes (i.e., low RHR and elevated HRR) indicate multiple processes within individuals or separate subtypes of antisocial adolescents is not certain. One hypothesis is that distinct subgroups of antisocial youth are characterized by unique patterns of autonomic activity. Studies of children and adolescents have provided some evidence that reactive aggression is linked to increased emotional reactivity as indexed by elevated HR and skin conductance reactivity to aversive stimuli (Hubbard et al., 2002; Pitts, 1996), whereas psychopathy has been linked to reduced skin conductance reactivity to aversive stimuli (Blair, 1999), and both psychopathy and proactive aggression have been linked to decreased reactivity to aversive stimuli as measured in attentional paradigms (Kimonis, Frick, Fazekas, \& Loney, 2006; Loney, Frick, Clements, Ellis, \& Kerlin, 2003). However, in the current study, we found that the effects of low RHR and HRR were the same whether we considered antisocial behavior in general, reactive violence, or nonviolent delinquency. The failure to find that the relation between antisocial behavior and cardiac activity was moderated by the subtype of antisocial behavior may be due to our using a community sample in which the correlations among the subtypes of antisocial behavior were quite high. Future work in this area may profit from examining these differences in groups that are extreme for reactive versus instrumental antisocial behavior.

An alternative explanation for the failure to find moderation by the subtype of antisocial behavior is that the cardiac measures might index the life course of antisociality rather than the subtype of behavior; for example, the cardiac measures may be differentially related to life-persistent versus adolescence-limited antisocial behavior (Moffitt \& Caspi, 2001). It may be that RHR, as an inherited and life-stable trait, is a characteristic of early starting, life-persistent antisocial behavior, whereas high HRR to provoca- tion stimuli is a characteristic that is acquired in development and is related to adolescence-limited antisocial behavior. This hypothesis awaits future inquiry.

SIP and antisocial behavior. The social-cognitive component of the multiprocess model is a pattern of deviant SIP responses to social stimuli. The results of this study are consistent with existing literature indicating a robust relation between deviant processing patterns and conduct problems in youth (Dodge et al., 1990; Guerra \& Slaby, 1989; Slaby \& Guerra, 1988). The current study is the first to examine the relation between processing patterns and antisocial behavior across time in late adolescence and extends previous work that has examined the relation between externalizing behavior problems across earlier developmental periods (Lansford et al., 2006). The observed pattern of bivariate correlations showed that deviant processing patterns were related both to concurrent and future antisocial behavior as well as to reactive and proactive aggression. As found with younger children, antisocial behavior in older adolescents is significantly associated with hostile attribution biases, self-defense goal identification, selection of aggressive responses to ambiguous provocations, and the positive evaluation of aggressive responses.

The current study is also the first to show among older adolescents that SIP measures predict future antisocial behavior even after controlling for past behavior. This finding has been demonstrated in younger children (Dodge, Pettit, Bates, \& Valente, 1995; Dodge, Pettit, McClaskey, \& Brown, 1986), but the current study indicates that dynamic relations between social-cognitive processes and antisocial behavior continue across development at least through adolescence. One implication is that assessing patterns of SIP in antisocial adolescents may be helpful to clinicians for determining which antisocial youth are most at risk for exhibiting increased antisocial offending. In addition, deviant processing patterns represent a target for therapeutic interventions.

Dynamic relations among SIP, ANS reactivity, and antisocial behavior. Perhaps the most notable finding from this study is that social-cognitive patterns are significantly related to measures of ANS reactivity. The bivariate relations show that elevated HRR is significantly associated with accessing aggressive responses from memory and positively evaluating aggressive responses in male adolescents and positively related to self-defense goal identification in female adolescents. An additional unexpected finding was that elevated RHR was significantly related both to accessing aggressive responses from memory and to positively evaluating aggressive responses in female adolescents. SEM models revealed that the social-cognitive responses mediated the effect of HRR and elevated RHR on antisocial behavior. Because social-cognitive responses and cardiac reactivity were measured simultaneously, we cannot determine the direction of effects between HRR and deviant SIP. The findings are consistent with the hypothesis that cardiac reactivity and SIP are closely related and partially mediate each other's effect on antisocial behavior. This model is consistent with studies that have experimentally manipulated either cognition or affect and demonstrated bidirectional effects (e.g., Ochsner, Bunge, Gross, \& Gabrieli, 2002; Zillmann, Bryant, Cantor, \& Day, 1975 ) and with theoretical work that has hypothesized interrelations between cognitive and affective processes (de Castro, 2004; Lemerise \& Arsenio, 2000; Metcalfe \& Mischel, 1999).

Overall, the findings are consistent with a model in which physiological arousal contributes to antisocial behavior through 
two distinct processes. The first process is a trait-like pattern in which low RHR predicts high antisocial behavior that is not mediated by cognitive processes as assessed here. Children whose antisocial behavior emerges from this process are likely to be fearless, manipulative, and undeterred by the possibility of retaliation or punishment. In support of this trait-like hypothesis, Moffit and Caspi (2001) found that low RHR predicted behavior problems only in the $10 \%$ of the male participants in their longitudinal sample who exhibited life course-persistent antisocial behavior and that low RHR was not a predictor of adolescent-limited conduct problems.

The second process reflects a component of cardiac hyperreactivity to provocations (and perhaps even to mild stressors for some youths) that is related to deviant SIP and exerts indirect effects on antisocial behavior. This effect is hypothesized to be bidirectional; that is, elevated arousal may cause activation of associated patterns of SIP ("hot" system tuning "cool" system processes on the basis of innate and/or learned associations between arousal and patterns of social cognition) and, conversely, patterns of deviant SIP may cause elevated arousal ("cool" system recruiting "hot" system processes also on the basis of innate and/or learned associations).

Further research is needed to clarify the robustness of this multiprocess model and to examine the developmental trajectories of these processes. We hypothesize that the process involving low RHR is driven by temperament and is not related to life experiences, whereas HRR grows out of life experiences involving adversity to the self (e.g., early physical abuse or chronic social rejection).

This model has implications for clinical intervention with antisocial youths. Interventions with individuals displaying callous instrumental antisocial behavior may require relatively more emphasis on developing prosocial values and beliefs, whereas interventions with individuals exhibiting emotionally reactive antisocial behavior may require relatively more emphasis on awareness of physiological arousal, increasing benign attributions of others' behavior, emotion regulation, and impulse control.

\section{Antisocial Behavior in Female Adolescents}

The findings indicate that antisocial behavior in female adolescents is directly related to deviant social-cognitive patterns and indirectly related to elevated RHR and elevated HRR via the effects of these measures on deviant social cognition. The main differences from the findings for male adolescents are that the social-cognitive measures were not as strongly related to antisocial behavior in female adolescents, the direct negative effect of RHR on antisocial behavior was not found for female adolescents, and the model explained a smaller percentage of variance in antisocial behavior for female than for male adolescents.

Although not as strong, the findings linking deviant SIP to antisocial behavior in female adolescents are consistent with patterns discovered in younger female individuals (e.g., Dodge et al., 1986, 1995) and with male adolescents in the current study. The significant gender moderation of the relation between RHR and antisocial behavior stands in contrast to several previous studies that have found a negative relation between RHR and antisocial behavior in both male and female participants (Maliphant et al., 1990; Raine et al., 1997; Rogeness et al., 1990). However, if low RHR is specifically a marker of more severe life course-persistent antisocial behavior, then the null findings from the current study may reflect the low prevalence of female participants exhibiting this type of behavior in the current community sample. This would be consistent with the findings of Moffitt and Caspi (2001) that only $1 \%$ of the female participants in their study were classified as being in the life course-persistent group.

The observation that main study models accounted for less of the variance in antisocial behavior in female than in male participants may reflect the emphasis of study measures on overt antisocial behavior, which is more common in male individuals, rather than on relational antisocial behavior, which is relatively more common among female individuals (Dodge et al., 2006). Future work may profit from examining the coordination of socialcognitive and physiological processes in types of antisocial behavior that are more prevalent among female individuals. Nonetheless, the general findings from the current study are largely consistent for male and female individuals.

\section{Limitations and Directions for Future Research}

The current study has several limitations. First, it was not designed in a manner that would allow a more specific examination of the directionality of the relation between autonomic activity and patterns of SIP. As this effect is hypothesized to be bidirectional and to unfold in microseconds, experimental studies are needed to examine the relation in both directions. Second, the current study examined how self-regulatory processes such as autonomic nervous system activity and social cognition are related across participants. The results were then used to make inferences about intraperson regulatory processes. This is a leap of conclusion that warrants further within-person inquiry. Future research in this area would benefit from study designs that allowed more detailed analyses of the intraperson processes of self-regulation. Third, the current measures of autonomic nervous system activity and SIP should not be taken as exhaustive assessments of these domains. It is plausible that different patterns of correlation and mediation would be found if different measures within these domains had been assessed. For example, skin conductance and vagal tone might yield different effects of ANS activity, and social-cognitive responses to other types of stimuli might yield different correlates with ANS activity.

Yet another limit is that it is not clear whether cardiac reactivity as assessed here reflects a more general reactivity process or reactivity specifically to provocations to the self. Future studies should assess participants' psychophysiological responses to a range of social and nonsocial stimuli, with varying demands on participants to respond verbally to questions (or not), in order to parse the actual reactivity effect discovered here.

Finally, the distinct correlates of RHR and HRR beg for future inquiry to understand the origins of these individual differences. Previous research suggests that RHR is highly stable and may reflect a trait-like process rooted in inherited characteristics. Less is known about individual differences in high HRR to provocations. Because this pattern was found to be significantly correlated with hostile attributional biases, accession of aggressive responses, and positive evaluations of aggressive behavior, all of which have been found to have antecedents in life experiences of early physical maltreatment (Dodge et al., 1990) and chronic peer/social rejection (Dodge et al., 2003), it is hypothesized that high HRR to 
provocations will emerge from early life experiences of adversity. This is a topic for future inquiry.

\section{References}

Achenbach, T. M. (1991a). Manual for the child behavior checklist 4-18 and 1991 profile. Burlington, VT: Department of Psychiatry, University of Vermont.

Achenbach, T. M. (1991b). Manual for the youth self-report and 1991 profile. Burlington, VT: Department of Psychiatry, University of Vermont.

Behrman, R. E., Kliegman, R. M., \& Jenson, H. B. (2000). Nelson textbook of pediatrics (16th ed.). Philadelphia: W. B. Saunders.

Blair, R. (1999). Responsiveness to distress cues in the child with psychopathic tendencies. Personality and Individual Differences, 27(1), 135145 .

Blair, R. J. R. (2004). The roles of the orbital frontal cortex in the modulation of antisocial behavior. Brain and Cognition, 55, 198-208.

Brennan, P. A., Raine, A., Schulsinger, F., Kirkegaard-Sorensen, L., Knop, J., Hutchings, B., et al. (1997). Psychophysiological protective factors for male subjects at high risk for criminal behavior. American Journal of Psychiatry, 154(6), 853-855.

Burks, V. S., Laird, R. D., Dodge, K. A., Pettit, G. S., \& Bates, J. E. (1999). Knowledge structures, social information processing, and children's aggressive behavior. Social Development, 8(2), 220-236.

Cohen, J., \& Cohen, P. (1983). Applied multiple regression/correlation analysis for the behavioral sciences (2nd ed.). Hillsdale, NJ: Erlbaum.

Cohen, S., \& Hamrick, N. (2003). Stable individual differences in physiological response to stressors: Implications for stress-elicited changes in immune related health. Brain Behavior and Immunity, 17(6), 407-414.

Crick, N. R., \& Dodge, K. A. (1994). A review and reformulation of social information-processing mechanisms in children's social adjustment. Psychological Bulletin, 115(1), 74-101.

de Castro, B. O. (2004). The development of social information processing and aggressive behaviour: Current issues. European Journal of Developmental Psychology, 1(1), 87-102.

de Castro, B. O., Slot, N. W., Bosch, J. D., Koops, W., \& Veerman, J. W. (2003). Negative feelings exacerbate hostile attributions of intent in highly aggressive boys. Journal of Clinical Child and Adolescent Psychology, 32(1), 56-65.

de Castro, B. O., Veerman, J. W., Koops, W., Bosch, J. D., \& Monshouwer, H. J. (2002). Hostile attribution of intent and aggressive behavior: A meta-analysis. Child Development, 73(3), 916-934.

Dodge, K. A., Bates, J. E., \& Pettit, G. S. (1990). Mechanisms in the cycle of violence. Science, 250(4988), 1678-1683.

Dodge, K. A., Coie, J. D., \& Lynam, D. R. (2006). Aggression and antisocial behavior in youth. In W. Damon (Series Ed.) \& N. Eisenberg (Vol. Ed.), Handbook of child psychology: Vol. 3. Social, emotional, and personality development (6th ed., pp. 719-788). New York: Wiley.

Dodge, K. A., Lansford, J. E., Burks, V. S., Bates, J. E., Pettit, G. S., Fontaine, R., et al. (2003). Peer rejection and social informationprocessing factors in the development of aggressive behavior problems in children. Child Development, 74(2), 374-393.

Dodge, K. A., Lochman, J. E., Harnish, J. D., Bates, J. E., \& Pettit, G. S. (1997). Reactive and proactive aggression in school children and psychiatrically impaired chronically assaultive youth. Journal of Abnormal Psychology, 106(1), 37-51.

Dodge, K. A., \& Pettit, G. S. (2003). A biopsychosocial model of the development of chronic conduct problems in adolescence. Developmental Psychology, 39(2), 349-371.

Dodge, K. A., Pettit, G. S., Bates, J. E., \& Valente, E. (1995). Social information-processing patterns partially mediate the effect of early physical abuse on later conduct problems. Journal of Abnormal Psychology, 104(4), 632-643.
Dodge, K. A., Pettit, G. S., McClaskey, C. L., \& Brown, M. M. (1986). Social competence in children. Monographs of the Society for Research in Child Development, 51(2), 1-85.

Dodge, K. A., \& Schwartz, D. (1997). Social information processing mechanisms in aggressive behavior. In D. M. Stoff, J. Breiling, \& J. D. Maser (Eds.), Handbook of antisocial behavior (pp. 171-180). New York: Wiley.

Dodge, K. A., \& Somberg, D. R. (1987). Hostile attributional biases among aggressive boys are exacerbated under conditions of threats to the self. Child Development, 58(1), 213-224.

Farrington, D. P. (1987). Early precursors of frequent offending. In J. Q. Wilson \& G. C. Loury (Eds.), From children to citizens: Vol. 3. Families, schools, and delinquency prevention (pp. 42-64). London: Springer-Verlag.

Fontaine, R. G., Burks, V. S., \& Dodge, K. A. (2002). Response decision processes and externalizing behavior problems in adolescents. Development and Psychopathology, 14(1), 107-122.

Fontaine, R. G., \& Dodge, K. A. (2006). Real-time decision making and aggressive behavior in youth: A heuristic model of response evaluation and decision (RED). Aggressive Behavior, 32(6), 604-624.

Fontaine, R. G., \& Dodge, K. A. (in press). The transactional development of individual social-information processing and aggressive behavior. In A. J. Sameroff (Ed.), Transactional processes in development. Washington, DC: American Psychological Association.

Gouze, K. R. (1987). Attention and social problem solving as correlates of aggression in preschool males. Journal of Abnormal Child Psychology, $15,181-197$.

Guerra, N. G., \& Slaby, R. G. (1989). Evaluative factors in social problem solving by aggressive boys. Journal of Abnormal Child Psychology, 17(3), 277-289.

Hollingshead, A. A. (1979). Four-factor index of social status. Unpublished manuscript.

Hubbard, J. A., Smithmyer, C. M., Ramsden, S. R., Parker, E. H., Flanagan, K. D., Dearing, K. F., et al. (2002). Observational, physiological, and self-report measures of children's anger: Relations to reactive versus proactive aggression. Child Development, 73(4), 1101-1118.

Kimonis, E. R., Frick, P. J., Fazekas, H., \& Loney, B. R. (2006). Psychopathy, aggression, and the processing of emotional stimuli in non-referred girls and boys. Behavioral Sciences \& the Law, 24(1), 21-37.

Lansford, J. E., Malone, P. S., Dodge, K. A., Crozier, J. C., Pettit, G. S., \& Bates, J. E. (2006). A 12-year prospective study of patterns of social information processing problems and externalizing behaviors. Journal of Abnormal Child Psychology, 34(5), 709-718.

Lemerise, E. A., \& Arsenio, W. F. (2000). An integrated model of emotion processes and cognition in social information processing. Child Development, 71(1), 107-118.

Lensvelt-Mulders, G., \& Hettema, J. (2001). Genetic analysis of autonomic reactivity to psychologically stressful situations. Biological Psychology, $58(1), 25-40$

Loney, B. R., Frick, P. J., Clements, C. B., Ellis, M. L., \& Kerlin, K. (2003). Callous-unemotional traits, impulsivity, and emotional processing in adolescents with antisocial behavior problems. Journal of Clinical Child and Adolescent Psychology, 32(1), 66-80.

Lorber, M. F. (2004). Psychophysiology of aggression, psychopathy, and conduct problems: A meta-analysis. Psychological Bulletin, 130(4), $531-552$.

MacKinnon, D. P., Lockwood, C. M., Hoffman, J. M., West, S. G., \& Sheets, V. (2002). A comparison of methods to test mediation and other intervening variable effects. Psychological Methods, 7(1), 83-104.

Maliphant, R., Hume, F., \& Furnham, A. (1990). Autonomic nervous system (ANS) activity, personality characteristics and disruptive behaviour in girls. Journal of Child Psychology and Psychiatry, 31(4), 619628

Metcalfe, J., \& Mischel, W. (1999). A hot/cool-system analysis of delay of 
gratification: Dynamics of willpower. Psychological Review, 106(1), 3-19.

Mezzacappa, E., Tremblay, R. E., Kindlon, D., Saul, J., Arseneault, L., Seguin, J., et al. (1997). Anxiety, antisocial behavior, and heart rate regulation in adolescent males. Journal of Child Psychology and Psychiatry, 38(4), 457-469.

Moffitt, T. E., \& Caspi, A. (2001). Childhood predictors differentiate life-course persistent and adolescence-limited antisocial pathways among males and females. Development and Psychopathology, 13(2), 355-375.

Muthén, L. K., \& Muthén, B. O. (1998-2004). Mplus user's guide (3rd ed.). Los Angeles: Muthén \& Muthén.

Ochsner, K. N., Bunge, S. A., Gross, J. J., \& Gabrieli, J. D. (2002), Rethinking feelings: An fMRI study of the cognitive regulation of emotion. Journal of Cognitive Neuroscience, 14(8), 1215-1229.

Ortiz, J., \& Raine, A. (2004). Heart rate level and antisocial behavior in children and adolescents: A meta-analysis. Journal of the American Academy of Child \& Adolescent Psychiatry, 43(2), 154-162.

Pitman, R. K., Gilbertson, M. W., Gurvits, T. V., May, F. S., Lasko, N. B., Metzger, L. J., et al. (2006). Clarifying the origin of biological abnormalities in PTSD through the study of identical twins discordant for combat exposure. In R. Yehuda (Ed.), Psychobiology of posttraumatic stress disorders: A decade of progress. Annals of the New York Academy of Science (Vol. 1071, pp. 242-254).

Pitts, T. B. (1996). Reduced heart rate levels in aggressive children. In A. Raine, P. A. Brennan, D. P. Farrington, \& S. A. Mednick (Eds.), Biosocial bases of violence (pp. 317-320). New York: Plenum Press.

Porges, S. W., Doussard-Roosevelt, J. A., Portales, A., \& Greenspan, S. I. (1996). Infant regulation of the vagal "brake" predicts child behavior problems: A psychobiological model of social behavior. Developmental Psychobiology, 29(8), 697-712.

Raine, A. (1993). The psychopathology of crime. San Diego, CA: Academic Press.

Raine, A. (1996). Autonomic nervous system activity and violence. In D. M. Stoff \& R. B. Cairns (Eds.), Aggression and violence: Genetic, neurobiological, and biosocial perspectives (pp. 145-168). Mahwah, NJ: Erlbaum.

Raine, A. (2002). Annotation: The role of prefrontal deficits, low autonomic arousal and early health factors in the development of antisocial and aggressive behavior in children. Journal of Child Psychology and Psychiatry, 43(4), 417

Raine, A., Dodge, K., Loeber, R., Gatzke-Kopp, L., Lynam, D., Reynolds,
C., et al. (2006). The reactive-proactive aggression questionnaire: Differential correlates of reactive and proactive aggression in adolescent boys. Aggressive Behavior, 32(2), 159-171.

Raine, A., Venables, P. H., \& Mednick, S. A. (1997). Low resting heart rate at age 3 years predisposes to aggression at age 11 years: Evidence from the Mauritius Child Health Project. Journal of the American Academy of Child \& Adolescent Psychiatry, 36(10), 1457-1464.

Raine, A., Venables, P. H., \& Williams, M. (1990). Relationships between central and autonomic measures of arousal at age 15 years and criminality at age 24 years. Archives of General Psychiatry, 47(11), 10031007.

Raine, A., Venables, P. H., \& Williams, M. (1995). High autonomic arousal and electrodermal orienting at age 15 years as protective factors against criminal behavior at age 29 years. American Journal of Psychiatry, 152(11), 1595-1600.

Rogeness, G. A., Cepeda, C., Macedo, C. A., Fischer, C., \& Harris, W. R. (1990). Differences in heart rate and blood pressure in children with conduct disorder, major depression, and separation anxiety. Psychiatry Research, 33(2), 199-206.

Scarpa, A., Raine, A., Venables, P. H., \& Mednick, S. A. (1997). Heart rate and skin conductance in behaviorally inhibited Mauritian children. Journal of Abnormal Psychology, 106(2), 182-190.

Slaby, R. C., \& Guerra, N. G. (1988). Cognitive mediators of aggression in adolescent offenders: 1. Assessment. Developmental Psychology, 24, $580-588$.

Suarez, E. C., Kuhn, C. M., Schanberg, S. M., Williams, R. B., Jr., \& Zimmermann, E. A. (1998). Neuroendocrine, cardiovascular, and emotional responses of hostile men: The role of interpersonal challenge. Psychosomatic Medicine, 60(1), 78-88.

Wadsworth, M. E. J. (1976). Delinquency, pulse rate, and early emotional deprivation. British Journal of Criminology, 16, 245-256.

Welsh, G. S. (1956). Factor dimensions A and R. In G. S. Welsh \& W. G. Dahlstrom (Eds.), Basic readings on the MMPI in psychology and medicine (pp. 264-281). Minneapolis, MN: University of Minnesota Press.

Zillmann, D., Bryant, J., Cantor, J. R., \& Day, K. D. (1975). Irrelevance of mitigating circumstances in retaliatory behavior at high levels of excitation. Journal of Research in Personality, 9(4), 282-293.

Received February 15, 2007

Revision received August 3, 2007

Accepted October 9, 2007 